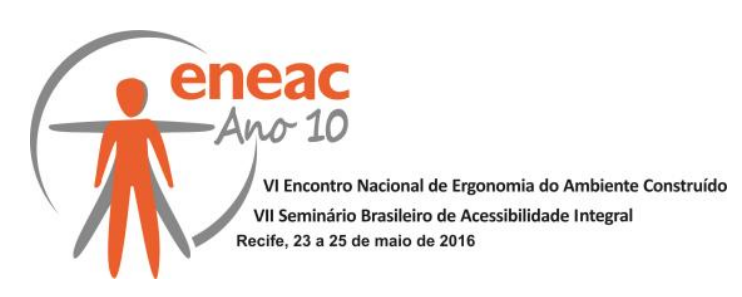

\title{
AVALIAÇÃO ERGONÔMICA EM LOJAS DE ROUPAS FEMININAS PLUS SIZEE- ESTUDOS DE CASO EM CARUARU E JOÃO PESSOA
}

\author{
SERRÃO, Helena de Cássia Nogueira(1); \\ SILVA JÚNIOR, José Adilson(2); \\ SARMENTO, Thaisa Francis César Sampaio (3); \\ VILLAROUCO, Vilma (4) \\ (1) Instituto Federal da Paraíba, Prof ${ }^{a}$ Msc. Curso Superior em Design de Interiores \\ e-mail: helenacpn@msn.com \\ (2) Universidade Federal de Pernambuco, Graduado em Design \\ e-mail: silvajunior.adilson@hotmail.com \\ (3) Universidade Federal de Alagoas, Prof ${ }^{a}$ Msc Faculdade de Arquitetura e Urbanismo \\ e-mail: thaisasampaio@hotmail.com \\ (4) Universidade Federal de Pernambuco, Prof. ${ }^{\text {a }}$ Dr- PPG em Design \\ e-mail: villarouco@hotmail.com

\begin{abstract}
RESUMO
A oferta de roupas plus size aumentou nos últimos anos, como reflexo da segmentação do mercado de moda, para atingir as necessidades de um público exclusivo, mas crescente, que apresenta necessidades dimensionais e de modelagem específicas, comumente não encontradas em roupas de grandes marcas. As lojas de roupas plus size visam oferecer um atendimento diferenciado e produtos adequados, entretanto, os espaços em que essas lojas estão instaladas nem sempre oferecem as condições de acessibilidade e de conforto necessárias. Esta pesquisa utiliza a MEAC - Metodologia Ergonômica para o Ambiente Construído - para avaliar as condições ergonômicas de duas lojas de roupas plus size, e propor diretrizes de melhorias para estes ambientes.
\end{abstract}

Palavras chave: Ergonomia do ambiente construído; Espaço comercial; Percepção do usuário; vestuário plus size.

\begin{abstract}
In recent years, plus size clothing market has increased. It is caused by segmentation of the fashion market, in order to attendthe needs of an exclusive and growing public. These peoplefeature dimensional and modeling specific clothing design, often not found in big brand clothing stores. Plus sizeclothing stores are prepared to provide a differentiated service and suitable products offers, however, theirinterior design are not always accessible or comfort.This research uses the MEAC Ergonomic Methodology for the Built Environment to evaluate ergonomics environmental conditions, and user's satisfaction perceptions into twoplus size clothing stores. As results, it will propose guidelines for improvements to these environments.
\end{abstract}

Keywords:Ergonomics for built environment;storesinterior design; user's perception, plus size clothing. 


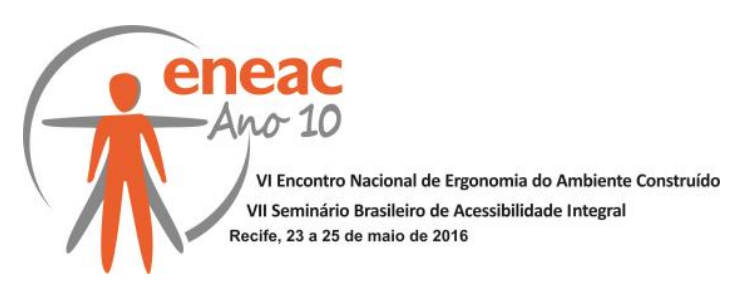

\section{INTRODUÇÃO}

A obesidade é um problema crescente nas sociedades ocidentais. As questões que envolvem a aparência apontam para um padrão de comparação entre as pessoas comuns e os modelos sociais considerados perfeitos, divulgados amplamente pela mídia de TV, de internet e das revistas de moda.

Ser uma pessoa obesa, ou com sobrepeso, implica em lidar com preconceito social, ter dificuldades em encontrar peças de vestuário que estejam adequados com a tendência de moda, e principalmente encontrar lojas, marcas ou fornecedores que possam atender os desejos e vaidades femininas, sem desprezar o conforto, o bem-estar e a modelagem adequada aos padrões estéticos não convencionais, contraditoriamente, com crescente número de consumidores.

A necessidade de oferta de roupas plus size ocorreram nos últimos anos, como reflexo dessa segmentação do mercado de moda, para atingir as necessidades de um público exclusivo, mas crescente. Este público apresenta necessidades dimensionais e de modelagem específicas, que comumente não são trabalhados como público-alvo das grandes marcas, ou das grandes lojas de roupas no país.

Nesse sentido, as lojas de roupas plus size, principalmente para o público feminino, visam oferecer um atendimento diferenciado, produtos adequados às necessidades de seus clientes. Entretanto, os espaços em que essas lojas estão instaladas nem sempre oferecem as condições de acessibilidade e de conforto compatíveis com as recomendações apontadas nas normas específicas.

É com o objetivo de investigar as condições ergonômicas de ambientes comerciais de roupas femininas plus size, que esta pesquisa pretende analisar duas lojas. A Loja 1, objeto desta pesquisa, localiza-se em João Pessoa - PB, num ponto comercial no centro da cidade, onde ocorre grande fluxo de transeuntes. A loja 2, objeto desta pesquisa, localiza-se em Caruaru - PE, localizada numa galeria comercial de grande movimentação de pessoas. Ambas as lojas têm fachadas envidraçadas, com boa visualização das calçadas em que estão localizadas.

\section{REFERENCIAL TEÓRICO}

De acordo com os dados da Organização Mundial da Saúde (OMS) observamos que a obesidade está se disseminando no mundo como uma "epidemia global" do século XXI denominado "globesidade" (OMS, 2004).

Essas pessoas têm diversas dificuldades no seu dia-a-dia. Desde realizar tarefas básicas, como subir um lance maior de degraus, amarrar os cadarços de sapatos, sentar em determinadas cadeiras, em cinemas, teatros e até mesmo em aviões. Considerando que em edificações, esses problemas persistem, mesmo em construções novas. Em alguns ambientes, a dificuldade de utilização é bastante agravada pelo dimensionamento menor que o mínimo previsto nas normas brasileiras de acessibilidade, a NBR 9050 (ABNT, 2015)e de ergonomia, NR-17 (MINISTÉRIO DO TRABALHO, s.d.), assim como, pela falta de elementos de acomodação e apoio aos usuários, principalmente em banheiros públicos, cabines sanitárias, escadas, e provadores de lojas.

O crescimento da obesidade é visível em ambos os gêneros, feminino e masculino. Em 2010 já se podia observar que o aumento de peso e, consequentemente, da obesidade ultrapassava $0,5 \%$ ao ano, somente no Brasil. Entre as mulheres, $25,4 \%$ apresentam sobrepeso entre 18 e 24 anos; 39,9\% entre 25 e 34 anos; e, entre 45 e 54 anos, o valor mais que dobra, se comparando com a juventude, passando para 55,9\%(SBEM, 2014). Um estudodo Ministério da Saúde nas capitais brasileiras constatou que 50,8\% da população 


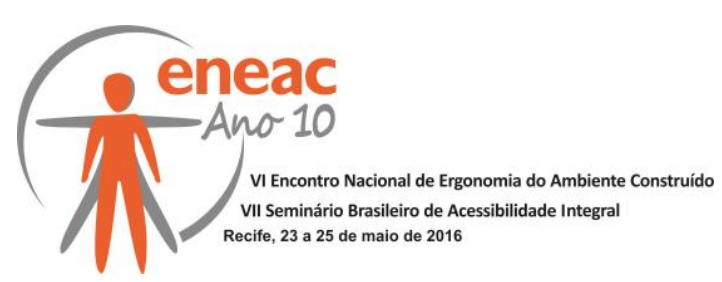

acima de 18 anos está com sobrepeso e 17,5\% está obesa (VALENÇA, 2014).

A roupa, ao longo do tempo, foi perdendo sua função utilitária para transformar-se em identitária, de pertencimento a determinados grupos sociais, de elevação da autoestima e, ao mesmo tempo, reflexo dos tempos e de definição de estilos de vida das sociedades da qual e para qual ela foi criada (COSTA, CARDOSO, 2007).Os corpos e a estética da beleza estão sendo observados e consumidos, assim como estão sendo consumidos os indivíduos dentro das sociedades atuais (BAUMAN, 2008), favorecendo a segmentação do mercado de moda, a criação de estilos e tendências que possam representar e oferecer produtos aos diferentes grupos sociais que se estabelecem na sociedade.

O corpo éo ponto de referência para toda ação que tomamos em direção as coisas, no espaço, ponto de toda percepção espacial. Os sentidos estabelecem conexão com as coisas, arranjando-as adequadamente a percepção e, consequentemente, a experiência espacial.

Segundo Malard (2006), a gênese do espaço arquitetônico decorre da espacialidade inerente ao ser humano: a existência humana tem uma dimensão espacial que é parte da própria experiência do homem no mundo, pois todas as ações humanas ocorrem no espaço. Concordando com Merleau-Ponty (1971), o espaço não é uma categoria apartada das coisas, mas um mediador de suas existências, uma condição preliminar para que as coisas sejam dispostas e conectadas, para que as coisas façam sentido. Isso implica numa relação de reciprocidade, nem as coisas podem ser compreendidas sem a noção de espacialidade, nem esta faz sentido fora de sua relação com as coisas.

A ergonomia é definida pela Associação Brasileira de Ergonomia - ABERGO, em consonância com a definição da InternationalErgonomicsAssociation, como uma disciplina relacionada ao entendimento das interações entre os humanos e outros elementos ou sistemas. Moraes e Mont'Alvão (2003) complementam que a ergonomia compõe conhecimento sobre habilidades, limitações e características humanas relevantes para o design.

A ergonomia busca o conhecimento das características humanas na projetação de sistemas que são abrigados em um ambiente. Desta forma, considera que o ambiente esteja adaptado ao homem. Como consequência, as metodologias ergonômicas se aproximam do usuário quando da avaliação de suas satisfações e insatisfações, em busca de respostas para os problemas do processo projetual (FALCÃO \& SOARES, 2011).

\section{METODOLOGIA}

Para esta pesquisa, foi utilizada a MEAC - Metodologia Ergonômica para o Ambiente Construído, desenvolvida por Villarouco (2011). A MEAC consiste em uma avaliação ergonômica que busca identificar conflitos ocasionados por elementos ausentes ou inadequados no ambiente, a partir das opiniões e sugestões dos próprios usuários, que são identificados através dos instrumentos de pesquisa da ergonomia, arquitetura e psicologia ambiental. Seu ponto de partida é a Análise Ergonômica do Trabalho - AET, e desenvolvese em quatro grandes etapas: Análise física;Análise da percepção do usuário;Diagnóstico ergonômico, e; Proposições Ergonômicas para o Ambiente.

\subsection{Análise Física:}

Esta etapa subdivide-se em 3 partes, discriminadas a seguir:

1) Análise Global do Ambiente - identificação da configuração ambiental mais abrangente, e a existência de problemas e de demandas que necessitem de uma intervenção ergonômica; 


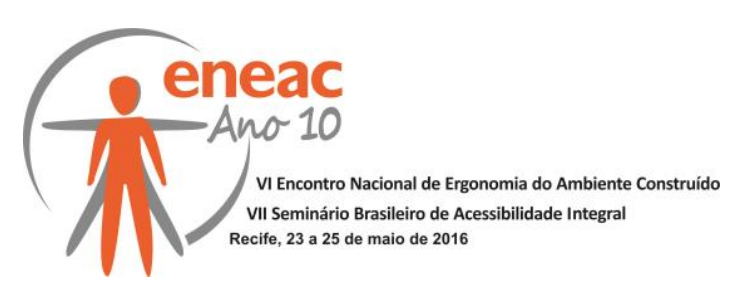

2) Identificação da Configuração Ambiental - identificação de todos os condicionantes físico-ambientais - dimensionamento, iluminação, ventilação, ruído, temperatura, fluxos, layout, deslocamentos, materiais de revestimento e condições de acessibilidade;

3) Avaliação do Ambiente em Uso - Verificação da sua usabilidade. Observação da execução das tarefas e atividades, com foco na antropometria, análise de postos de trabalho e do dimensionamento dos diversos elementos que compõe o ambiente.

Os critérios adotados para a Análise Física foram de acordo com os seguintes itens:

- Aferição dos índices de conforto ambiental - térmico, lumínico e acústico, através de instrumentos de aferição: Luxímetro Digital Minipa MLM-1011, Decibelímetro Digital Minipa MSL-1325 e Termoanemômetro Digital Minipa MDA II, em seguida foi feita a comparação com as condições recomendadas em normas da ABNT para desempenho acústico e lumínico. As normas de referência adotadas foram a NBR ISO/CIE 8995-1:2013 (lluminânciade ambientes de trabalho. Parte 1:Interiores), a NBR 10152/1999 (Avaliação do ruído ambiente em recintos de edificaçõesvisando o conforto dos usuários -Procedimento) e para aferição das condições de temperatura interna foram adotados os índices indicados na NR 17, a qual recomenda que a temperatura efetiva deve ser entre $20^{\circ} \mathrm{C}$ (vinte) e $23^{\circ} \mathrm{C}$ (vinte e três graus centígrados). As condições recomendadas em norma são descritas nasTabelas 01 e 02 , a seguir.

Tabela 01 - Recomendações para iluminância em ambientes internos - varejo.

\begin{tabular}{|l|c|c|c|}
\hline AMBIENTE/ATIVIDADE & $\begin{array}{c}\text { ILUMINÃNCIA } \\
\text { MANTIDA (LUX) }\end{array}$ & $\begin{array}{c}\text { íNDICE LIMITE DE } \\
\text { OFUSCAMENTO } \\
\text { (URGL) }\end{array}$ & $\begin{array}{c}\text { INDICE DE } \\
\text { REPRODUÇÃO } \\
\text { DE COR MíNIMO } \\
\left(\mathbf{R}_{\mathbf{a}}\right)\end{array}$ \\
\hline ÁREA DE VENDAS - PEQUENA & 300 & 22 & 80 \\
\hline ÁREA DE VENDAS - GRANDE & 500 & 22 & 80 \\
\hline ÁREA DO CAIXA & 500 & 19 & 80 \\
\hline MESA DO EMPACOTADOR & 500 & 19 & 80 \\
\hline
\end{tabular}

Fonte: NBR ISSO/CIE 8995-1(2013)

Tabela 02 - Nível de ruído máximo para ambientes internos comerciais.

\begin{tabular}{|l|c|}
\hline TIPO DE RECINTO & $\begin{array}{c}\text { NIVEL DE RUIDO } \\
\text { AMBIENTE (dB) }\end{array}$ \\
\hline LOJAS DE DEPARTAMENTOS, OU EM SHOPPING CENTER & $40-50$ \\
\hline LOJAS DE PROMOÇÃO & $50-56$ \\
\hline
\end{tabular}

Fonte: NBR 10152 (1999)

- Verificação das condições de Acessibilidade e segurança - Levantamento dimensional dos espaços e das instalações de elementos de apoio a pessoa com deficiência, e também para verificação das condições de segurança individual em caso de emergências. Com relação a acessibilidade, alguns critérios específicos foram tomados com maior grau de importância: Acesso principal à loja; dimensionamento do balcão; Condição de acesso aos produtos expostos; dimensionamento e conforto de cabines; condições das circulações, escadas e/ou rampas; disposição de informações visuais, de espelhos; e condições dos banheiros;

- Verificação do dimensionamento e layout interno - Levantamento dimensional dos espaços e das circulações internas dos ambientes, a fim de verificar a qualidade e o espaçamentos para livre circulação de pessoas e de cadeirantes. Tais 


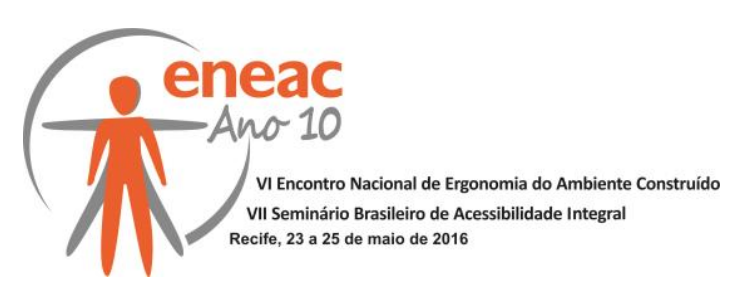

dimensões foram comparadas as condições dispostas na NBR 9050/2015, e de acordo com Panero e Zelnik (2003).

- Verificação da percepção do pesquisador - realizada na visita exploratória na etapa de Análise Global do Ambiente -Meac, a fim de colher as primeiras impressões sobre o ambiente e as suas condições de funcionamento;

- Análise de ambiente em uso - realizada através de registro fotográfico e entrevistas não estruturas, para perceber as condições do ambiente e de seus elementos no desempenho das atividades, as posturas adotadas e os problemas de inadequação.

\subsection{Análise da Percepção do Usuário:}

Para esta etapa foi aplicada a técnica do Poema dos Desejos (SANOFF, 1994). Seu objetivo é verificar julgamentos de aspectos funcionais, programáticos e estéticos, bem como a expectativa dos usuários para um ambiente/edificação ideal.Consisteem explorar a imaginação do entrevistado, pedindo-Ihes para completar a única instrução:'Eu gostaria que minha edificação tivesse/fosse...'.As respostas obtidas podem ser em desenhos ou frases, a depender das condições de colaboração, idade e interesse dos entrevistados. Para esta pesquisa, esta técnica foi aplicada junto às vendedoras das duas lojas avaliadas.

\subsection{Diagnóstico Ergonômico e Proposições Ergonômicas:}

Nestas últimas etapas da MEAC, o pesquisador elabora quadros analíticos dos principais resultados obtidos, sintetizando os principais problemas e elaborando diretrizes projetuais ou atitudinais para solucionar ou melhorar o desempenho dos espaços e de suas atividades e configurações.

\section{ANÁLISE DE DADOS}

Nesta pesquisa, foram analisadas duas lojas de roupas femininas plus size, durante o período de setembro a novembro de 2015. Foram realizadas quatro visitas a cada uma dessas lojas, que correspondem as análises descritas a seguir.

\subsection{Análise Global do Ambiente:}

LOJA 1 (em JOÃO PESSOA - PB):A loja situa-se numa rua comercial de grande fluxo de transeuntes. O espaço interno da loja parece ser bastante amplo, permitindo a livre circulação. São dois pavimentos, mas o atendimento ocorre no pavimento térreo. A loja dispõe de duas grandes araras, duas cabines, um banheiro, um balcão para atendimento e caixa, uma mesa central para acessórios, uma saleta para refeições e almoxarifado, e dois sofás para descanso dos clientes. $O$ acesso às roupas na arara é alto, podendo dificultar 0 manuseiodos cabides pelas clientes. Quanto ao conforto ambiental, o ambiente é claro e limpo, e a iluminação parecer estar adequada, a temperatura interna e ruído não foram percebidos como desconfortáveis.

LOJA 2 (em CARUARU - PE):O espaço interno é bem pequeno, mas há uma preocupação com o planejamento do layout. A loja não fecha para almoço, das $8 \mathrm{~h}$ às $13 \mathrm{~h}$ proprietária da loja, das $13 \mathrm{~h}$ às $18 \mathrm{~h}$ a única funcionária existente. O ambiente não aparenta ser barulhento nem desorganizado. Quanto ao mobiliário, tem-se um balcão de atendimento e caixa, duas araras para expor as roupas, um estar com duas poltronas e TV, um tapete preto redondo e um armário. Toda a fachada é composta de vidro, que forma a vitrine e a porta que dá acesso à loja. A predominância da cor branca contribui para a iluminação natural do ambiente. O pé direito, aparentemente, é muito alto.O nome da loja está localizado na 


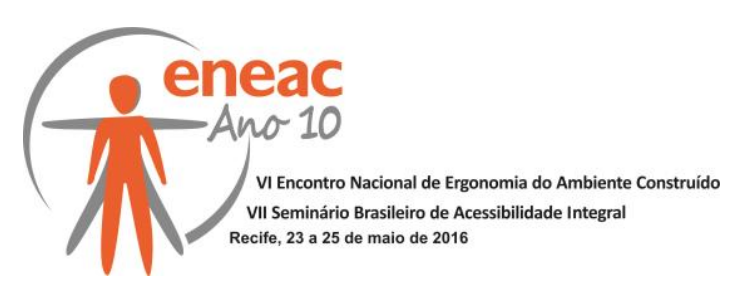

parede da fachada do primeiro andar, a loja possui a entrada recuada de modo que quem está caminhando na calçada não consegue enxergar o nome da loja.Os espelhos amplos, apoiados no piso, favorecem que todas as pessoas possam utilizá-lo com conforto.

\subsection{Análise da Configuração Ambiental:}

LOJA 1 (em João Pessoa - PB):A Loja 1 está localizada no centro de João Pessoa. Sua área é de $56,25 \mathrm{~m}^{2}$, no pavimento térreo, utilizado para o atendimento dos clientes, conforme Figura 1, a seguir.O acabamento interno é composto por: piso cerâmico de cor branca; teto em forro de gesso, na cor branco neve; paredes em alvenaria, pintadas também em branco.

A avaliação de Conforto Lumínico apontando para a fachada principal envidraçada à oeste, constatou-sea incidência de muita luz natural, que se projeta para o interior da loja sem nenhum dispositivo que lhe proporcione boa distribuição e controle, exceto pela presença de um toldo. Há a complementação com iluminação artificial de oito spots com lâmpadas econômicas em direção ao balcão, e dois pontos de luz sobre as araras. Na vitrine tem lâmpadas HQI, que são raramente utilizadas. Verificou-se a existência de três zonas lumínicas diferentes no estabelecimento, no pavimento térreo, onde se localiza a loja:Zona 1 -localizada a partir da vitrine até a projeção do mezanino (aferições de 3.000 a 4.000 lux);Zona 2 -localizada a partir da projeção do mezanino até o balcão de atendimento (aferições de 1.500 lux); e Zona 3 -localizada a partir do balcão de atendimento até a parede do depósito (aferições de 450 a 500 lux).

Figura 1 - Planta baixa e layout da Loja 1, em João Pessoa - PB.

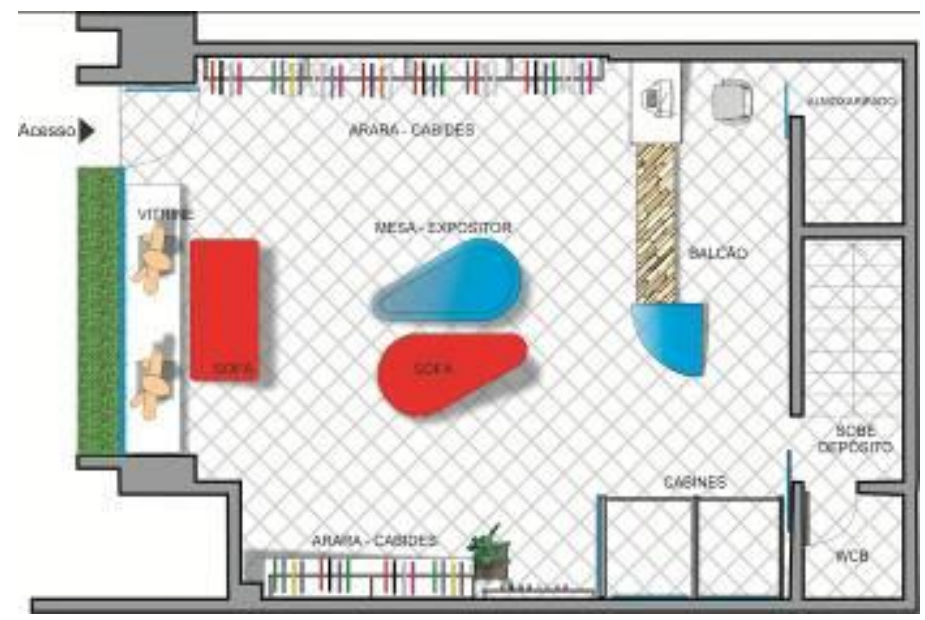

Fonte: os autores.

As iluminâncias pontuais aferidas foram: $\mathrm{Na}$ área do caixa -480 lux; Araras da lateral esquerda - 3080 lux a 1440 lux (redução no sentido exterior-interior da loja); Araras da lateral direita - 3270 lux a 1530 lux (redução no sentido exterior-interior da loja); Vitrine 3000 lux/4000 lux (iluminância atingida apenas com a luz natural); Provadores - 1400 lux / 1700 lux.Percebe-se que há excesso de iluminância no ambiente. A luz natural, praticamente dota a loja de autonomia lumínica, o que deveria ser algo positivo, entretanto, em excesso, contribui para o desconforto, devido aos fortes contrastes existentes entre as zonas lumínicas e sobre o produto exposto.

A avaliação do Conforto Acústicofoi avaliada em quatro zonas de ruído: $50 \mathrm{~dB} / 51 \mathrm{~dB}$ na Vitrine (que recebe pouco barulho externo, apesar de ser uma rua bastante movimentada); $53 \mathrm{~dB} / 58 \mathrm{~dB}$ no interior da loja (recebe influência do ar-condicionado Split); 60dB / 61dB na área do balcão (onde se localiza o equipamento de ar-condicionado); e51dB / 56dB no mezanino. 


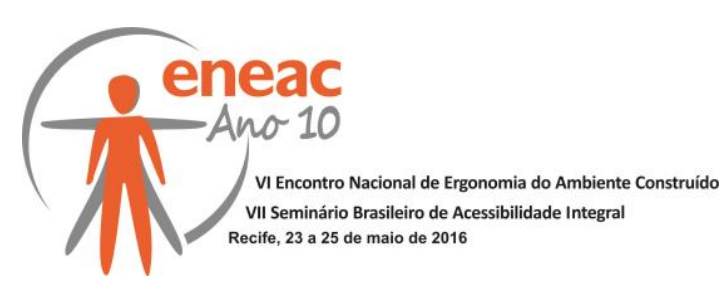

$\mathrm{Na}$ avaliação do Conforto Térmico, os ambientes foram medidos às $15 \mathrm{~h}$ e nenhum encontrou-se em atendimento à norma, apesar do salão ser dotado de um equipamento Split 60.000 Btus e o mezanino de outro equipamento de 35.000 Btus. Os valores obtidos foram: $26,8^{\circ} \mathrm{C}$ - Salão da loja; $26,3^{\circ} \mathrm{C}$ - Provadores; $25,7^{\circ} \mathrm{C}$ - Banheiro; $27,4^{\circ} \mathrm{C}-$ Mezanino. A excessiva insolação a qual a loja está submetida, bem como a ausência de meios de dissipação do calor excessivo, fazem com que a temperatura seja mais elevada.

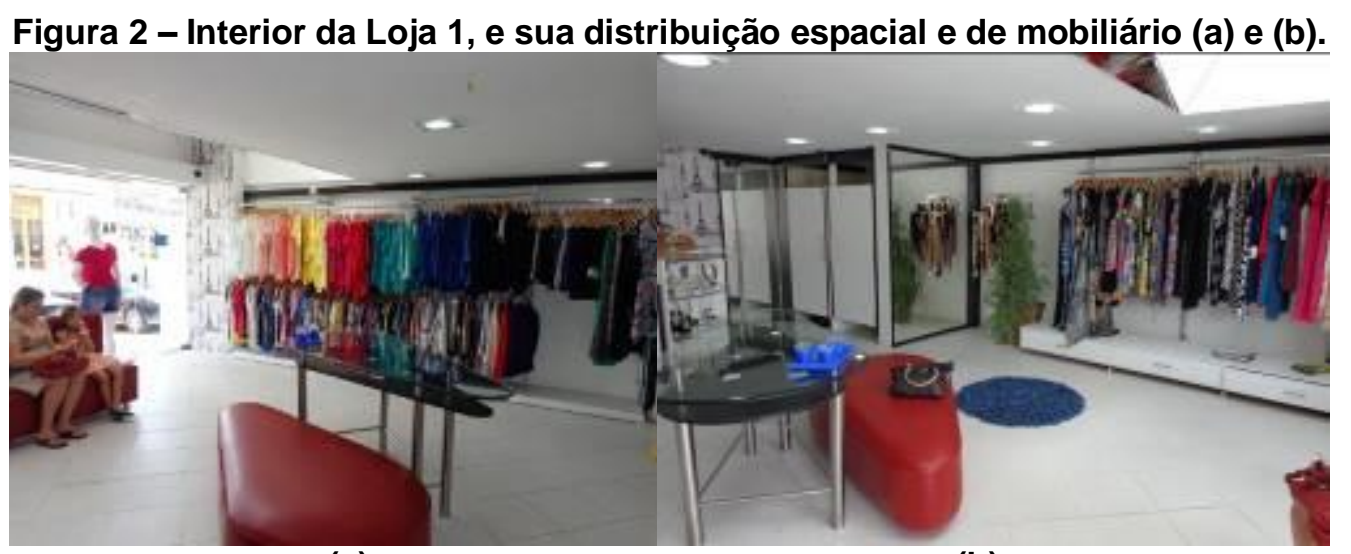

(a)

Fonte: os autores.

(b)

A avaliação das condições de acessibilidade, de acordo com a NBR 9050/2015, apontou para as seguintes descrições: o acesso é feito por uma porta de vidro, e a disposição dos elementos do layout é bastante ampla, permitindo a livre circulação; a loja dispõe de assentos confortáveis para clientes;o acesso as cabines, ao banheiro e ao almoxarifado é mais difícil, dada a largura das portas, e o dimensionamento interno em desconformidade com a NBR 9050/2015;0 acesso às roupas na arara é alto, dificultando o cliente de manusear os cabides;o balcão está em desconformidade com a NBR 9050/2015, pois sua altura não considera o atendimento a pessoas cadeirantes.

LOJA 2 (em CARUARU - PE):A Loja 2, situada na cidade de Caruaru - PE, ocupa uma área de $28 \mathrm{~m}^{2}$, de acordo com a planta baixa da Figura 3. O acabamento interno é composto por piso cerâmico de cor branca, teto em forro de gesso, com pintura branco neve, e paredes em alvenaria, pintadas também em branco. A cor rosa aparece nas paredes do provador, no painel de gesso onde encontra-se a TV, no mobiliário e nas prateleiras.

Figura 3 - Planta baixa e layout da loja 2, em Caruaru.

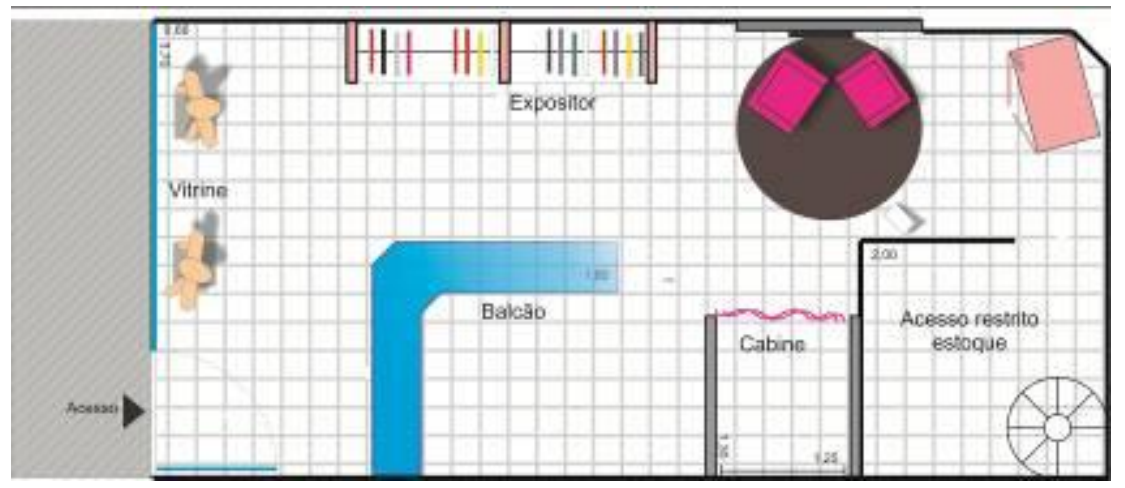

Fonte: os autores.

A avaliação do Conforto Lumínico foi aferida emonze pontos internos. Apenas trêsdesses pontos estavam dentro das recomendações médias de 500 lux. Oito pontos ficaram abaixo 


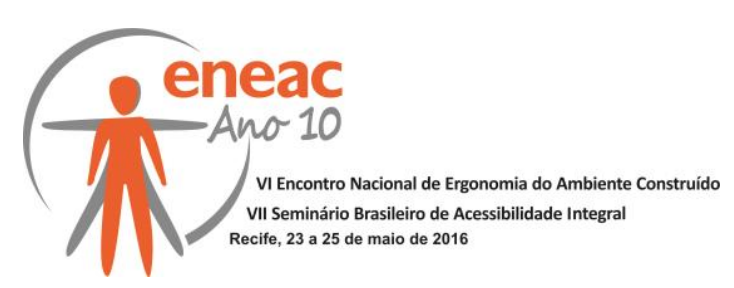

das recomendações, e outros três pontos obtiveram resultados inferiores a 300 lux, índice mínimo indicado pela norma.A predominância da cor branca e a fachada toda em vidro contribuem para a iluminação natural do ambiente. A iluminação artificial é feita por fluorescentes compactas instaladas no interior de plafons embutidos no forro de gesso. Aferições pontuais apontaram os seguintes resultados: 418 lux-computador; 586 lux entrada da loja; 811 lux -vitrine; 430 lux -expositor 1(arara); 315 lux - expositor 2 (arara); 144 lux- junto ao estoque/armário; 206 lux- provador; 230 lux- junto àspoltronas/TV; 413 lux- no centro da loja, 533 lux-junto aos manequins; e337 lux-sobre o balcão.

A avaliação doConforto Acústico foi aferida em três zonas, com os seguintes resultados: entre 62.1 e $69.5 \mathrm{~dB}$ junto ao computador (recebe influência do ruído externo da loja carros, motocicletas, pessoas); entre 59.9 e $60.6 \mathrm{~dB}$ junto a poltrona/TV; entre 62.2 a 64.7 $\mathrm{dB}$ junto a vitrine (recebe influência do ruído externo da loja - carros, motocicletas, pessoas).

A avaliação do Conforto Térmicofoi aferida em seis pontos internos. Nenhum deles enquadrou-se nos valores estabelecidos pela norma. $\mathrm{O}$ ambiente que obteve a temperatura mais baixa foi o provador, com $25^{\circ} \mathrm{C}$, e o espaço que obteve a maior temperatura, com $27^{\circ} \mathrm{C}$, foi a área do balcão onde há o computador, ferramenta de trabalho utilizada continuamente pela funcionária.

\section{Figura 4 - Configuração interna da Loja 2, em Caruaru - PE (a) espaço de estar e (b) balcão de} atendimento.

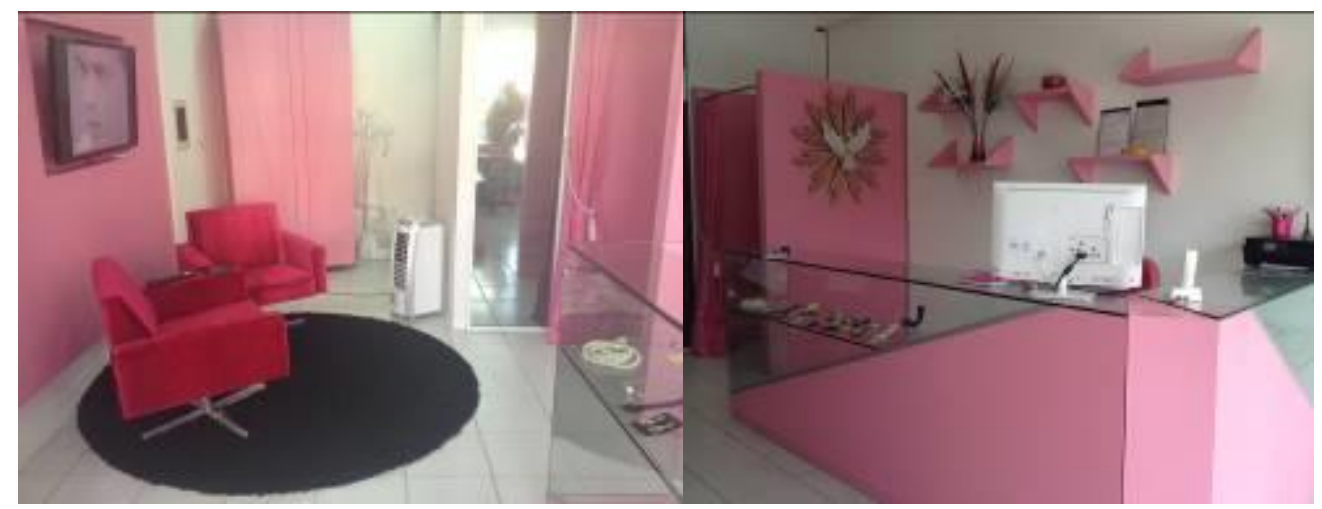

(a)

(b)

Fonte: os autores.

\subsection{Avaliação do Ambiente em Uso}

Para esta etapa foi utilizado o método MACHIA - Método de Avaliação da Circulação Horizontal Interna (SEABRA \&BARROS, 2013). Este método pretende verificar o ambiente através da simulação em planta baixa de bonecos antropométricos - sentado e de pé inseridos na execução de tarefas no ambiente, junto ao mobiliário, e na sobreposição de bonecos em circulação. Os bonecos de circulação são adotados em três cores diferenciadas. Verde para aquele que consegue desempenhar adequadamente a circulação livre de quaisquer barreiras, o amarelo para aquele que consegue desempenhar a tarefa de circulação com dificuldades, e o vermelho para aquele que não consegue desempenhar a atividade de circulação devido a riscos ou obstruções na circulação interna. Os resultados foram postos nos mapas das Figuras 5 e 6.

A Loja 1 foi considerada ampla, e na análise da circulação pelo método MACHIA (SEABRA \&BARROS, 2013) apresentou apenas três trechos de circulação restritiva e cinco trechos de circulação prejudicada (Figura 5). Já a Loja 2 foi considerada pequena, e na análise da circulação pelo MACHIA (op. cit.) apresentou maiores problemas de circulação, sendoum trecho de circulação restritiva e cinco trechos de circulação de risco (Figura 6). 


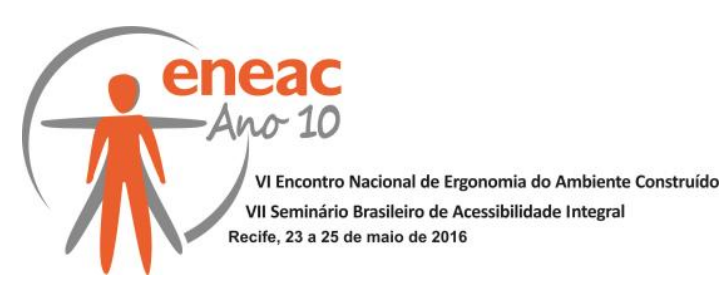

LOJA 1 (em João Pessoa - PB):A loja possui duas vendedoras e uma gerente que trabalham nos dois turnos, com intervalo de duas horas para descanso e almoço, alternados. Ambas as vendedoras vestem manequim acima do tamanho 50, em consonância com o conceito da loja. Entretanto, ambas têm dificuldades na realização de algumas tarefas, devido, inclusive, ao sobrepeso e as condições físicas do ambiente.A maior parte do tempo as vendedoras trabalham em pé, principalmente quando a gerente está presente, pois só há uma cadeira, uma vez que os demais assentos são para os clientes no salão. As vendedoras não relataram desconforto em acessar as araras das roupas, visto que ambas possuem altura superior a 1,70m. Entretanto, a existência de uma caixa de gavetas abaixo das araras no lado direito da loja, atrapalha um pouco o seu acesso.Um ponto de desconforto relatado foram as dimensões do banheiro e de sua porta de acesso, bem como a sua desorganização. No mezanino é possível encontrar mais situações desconfortáveis.

Figura 5 - Mapa Loja 1 (em João Pessoa - PB) detalhando o método MACHIA de circulação horizontal interna.

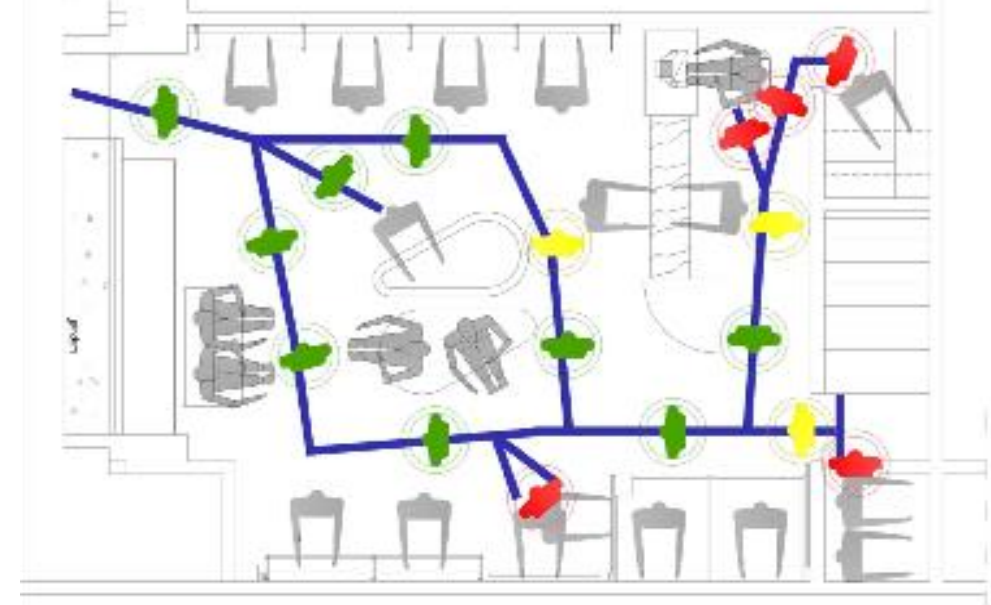

Fonte: os autores, adaptado de Seabra \& Barros (2013).

Figura 6 - Mapa Loja 2 (em Caruaru - PE) detalhando o método MACHIA de circulação horizontal interna.

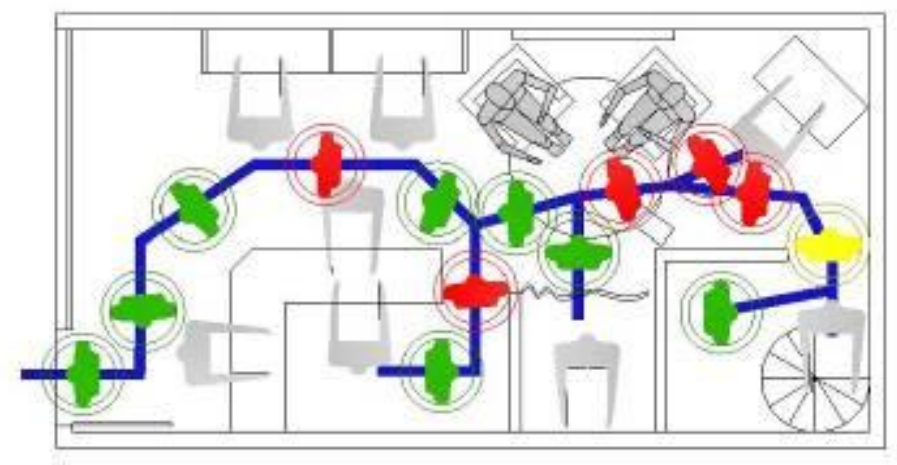

Fonte: os autores, adaptado de Seabra \& Barros (2013).

LOJA 2 (em CARUARU - PE): a única funcionária da loja segue uma jornada de trabalho de cinco horas por dia, das $13 \mathrm{~h}$ às $18 \mathrm{~h}$. O horário correspondente das $8 \mathrm{~h}$ às $13 \mathrm{~h}$ fica sob a responsabilidade da proprietária da loja.O posto de trabalho onde está localizado o computador é delimitado pelo mobiliário, um balcão em "L", com tampo de vidro e revestimento em laminado melamínico fosco na cor rosa.O modelo da cadeira utilizada no 


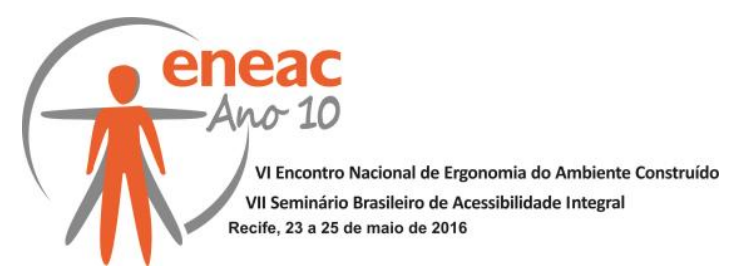

computador não possui apoio para braço. A presença de mobiliário com gavetas e as prateleiras localizadas abaixo do computador, prejudicam a movimentação das pernas da usuária.A fiação dos equipamentos de informática está localizada próximo ao pé da usuária, gerando riscos de acidentes. Observou-se ainda a ausência de um apoio adequado para os pés, uma vez que a usuária ora apoia os pés na base da cadeira, ora apoia na base do balcão.A funcionária apresenta dificuldade para alcançar as araras dos expositores e a última prateleira do armário utilizado para guardar as peças em estoque,para conseguir realizar tais atividades a usuária adota posturas inadequadas, como hiperextensão do pescoço e elevação dos membros superiores acima do nível dos ombros.

\subsection{Análise da Percepção do Usuário:}

A aplicaçãoda técnica Poema dos Desejos (SANOFF, 1994) apontou para os seguintes resultados:

Quadro 1 - Resultados obtidos com a aplicação do Poema dos Desejos, junto às funcionárias.

\begin{tabular}{|l|l|}
\hline \multicolumn{1}{|c|}{ LOJA 1 (em João Pessoa - PB) } & \multicolumn{1}{c|}{ LOJA 2 (em CARUARU - PE) } \\
\hline $\begin{array}{l}\text { Eu gostaria que a Ioja em que trabalho } \\
\text { fosse/tivesse... }\end{array}$ & $\begin{array}{l}\text { Eu gostaria que a minha loja fosse/tivesse... } \\
\text { (com a proprietária) }\end{array}$ \\
\hline $\begin{array}{l}\text { Resposta 1: Fosse mais refrigerada; Falta uma } \\
\text { geladeira para a gente guardar comida lanche, } \\
\text { almoço, etc.); Ser elaborado um projeto para o } \\
\text { móvel do caixa, pois não tenho onde colocar as } \\
\text { minhas pernas e fico com dores nas costas; Que } \\
\text { tivesse prateleiras na parte do estoque superior } \\
\text { para guardar melhor as coisas. }\end{array}$ & $\begin{array}{l}\text { Resposta 1: A proprietária demonstrou total } \\
\text { remprometimento com suas clientes ao } \\
\text { que sua loja deveria ter: "tudo o que minha } \\
\text { cliente precise em relação à produtos, espaço e } \\
\text { conforto". }\end{array}$ \\
\hline $\begin{array}{l}\text { Resposta 2: Ter geladeira; mais segurança na } \\
\text { escada - corrimão; A loja fosse mais refrigerada. }\end{array}$ & $\begin{array}{l}\text { Eu gostaria que a loja em que trabalho } \\
\text { fosse/tivesse...(com a funcionária) }\end{array}$ \\
\hline $\begin{array}{l}\text { Resposta 3: Geladeira; Estoque no térreo; Que } \\
\text { a loja fosse térrea, pois subir escada é muito } \\
\text { cansativo; a proprietária poderia comprar a loja } \\
\text { ao lado...( risos). }\end{array}$ & $\begin{array}{l}\text { Resposta 2: Mais espaço, mais provadores e } \\
\text { apoio/suporte para a cliente colocar as roupas } \\
\text { quando estiver no provador. }\end{array}$ \\
\hline
\end{tabular}

\subsection{Diagnóstico e proposições ergonômicas:}

Com base nas análises realizadas foram elaborados os quadros de diagnóstico e proposições ergonômicas para cada loja em questão.

Quadro 2 - Diagnóstico e proposições ergonômicas para Loja 1 (em João Pessoa - PB)

\begin{tabular}{|l|l|}
\hline \multicolumn{1}{|c|}{ DIAGNÓSTICO } & \multicolumn{1}{c|}{ PROPOSIÇÕES ERGONÔMICAS } \\
\hline Iluminação artificial excessiva & $\begin{array}{l}\text { Redimensionar potência das lâmpadas e separar } \\
\text { circuitos }\end{array}$ \\
\hline Provadores pequenos para cadeirantes & $\begin{array}{l}\text { Redimensionar provadores, torná-los mais } \\
\text { acessíveis }\end{array}$ \\
\hline Obstáculo frente ao espelho externo & Remover vegetação existente \\
\hline Banheiro obstruído por materiais de limpeza & Reorganizar materiais de limpeza e de manutenção \\
\hline $\begin{array}{l}\text { Balcão alto, sem assento para funcionárias, } \\
\text { local do caixa obstruindo acesso ao } \\
\text { almoxarifado }\end{array}$ & Dispor assentos (bancos) para funcionárias \\
\hline Almoxarifado muito estreito & $\begin{array}{l}\text { Por em desuso o almoxarifado, aumentando espaço } \\
\text { para o caixa }\end{array}$ \\
\hline Portas estreitas (banheiro e almoxarifado) & Instalar portas mais largas - 86cm. \\
\hline Excesso de luz natural incidindo na fachada & $\begin{array}{l}\text { Instalar dispositivo de controle da luz natural na } \\
\text { fachada externa da edificação }\end{array}$ \\
\hline
\end{tabular}




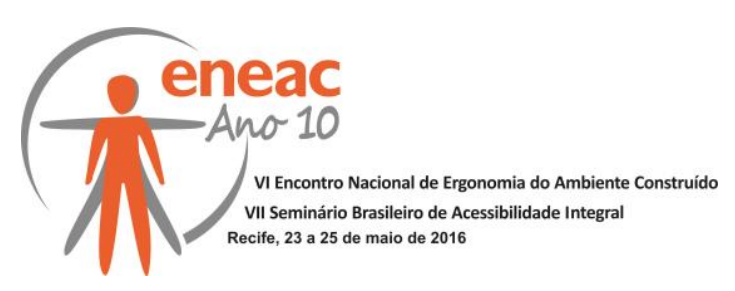

Área restrita a funcionários desconfortável, produtos e materiais de manutenção e limpeza obstruindo a circulação

Temperatura interna alta e desconfortável

Reorganizar espaço restrito aos funcionários, incluir aquisição de frigobar

Instalar condicionadores de ar, para uso em horários de maior desconforto

Quadro 3 - Diagnóstico e proposições ergonômicas para Loja 2 (em Caruaru - PE)

\begin{tabular}{|l|l|}
\hline \multicolumn{1}{|c|}{ DIAGNÓSTICo } & \multicolumn{1}{|c|}{ PROPOSIÇÕES ERGONÔMICAS } \\
\hline $\begin{array}{l}\text { Ruído externo excessivo, causando } \\
\text { desconforto }\end{array}$ & Proporcionar revestimentos absorvedores de ruído \\
\hline $\begin{array}{l}\text { lluminação insuficiente próximo ao estoque e } \\
\text { no provador }\end{array}$ & Instalação de novos pontos de luz \\
\hline Loja pequena e único provador & $\begin{array}{l}\text { Ampliar loja eliminando área restrita inutilizada e } \\
\text { instalar provadores mais espaçosos }\end{array}$ \\
\hline $\begin{array}{l}\text { Tapete e condicionador de ar obstruindo a } \\
\text { livre circulação }\end{array}$ & Remover tapete e condicionador de ar de piso \\
\hline $\begin{array}{l}\text { Balcão alto, assento desconfortável no caixa } \\
\text { e falta de apoio para os pés }\end{array}$ & $\begin{array}{l}\text { Readequar altura do balcão, substituir a cadeira e } \\
\text { incluir apoio para acomodar os pés }\end{array}$ \\
\hline $\begin{array}{l}\text { Falta apoio aos clientes no provador para } \\
\text { bolsas e roupas }\end{array}$ & Acrescentar puff como apoio no provador \\
\hline $\begin{array}{l}\text { Arara mal dimensionada para pessoas de } \\
\text { baixa estatura (funcionária) }\end{array}$ & Redimensionar a altura das araras \\
\hline Temperatura interna alta e desconfortável & $\begin{array}{l}\text { Instalar mais um condicionador de ar de parede, para } \\
\text { uso em horários de maior desconforto }\end{array}$ \\
\hline $\begin{array}{l}\text { Instalaçães elétricas subdimensionada e em } \\
\text { exposição no balcão }\end{array}$ & $\begin{array}{l}\text { Redimensionar pontos de tomada, abrigar a } \\
\text { instalação adequadamente e com segurança }\end{array}$ \\
\hline
\end{tabular}

\section{CONCLUSÃO}

As lojas de roupa plus size visitadas pretendem atender a um público feminino, que se preocupa com a escolha de roupas adequadas as suas dimensões corporais nas duas cidades, e oferecem condições razoáveis de conforto e de atendimento.

Os problemas encontrados nas análises levaram a percepção de necessidades de redimensionamento espacial, principalmente nos provadores, e ambientes de menor dimensão. Os problemas de conforto percebidos são recorrentes também em outros tipos de lojas - calor e ruído excessivos, iluminação inadequada, mobiliário ausente, ou inadequado para funcionários e também para clientes foram encontrados nas duas lojas.

A obtenção de dados da percepção dos usuários foi dificultada pela falta de conhecimento dos pontos problemáticos encontrados na Análise Física, ou pela dificuldade em expor opiniões próprias, com medo de represálias dos contratantes, tendo sido apontados poucos problemas. Não foram encontrados clientes nos momentos da coleta de dados de percepção dos usuários.

O diagnóstico ergonômico apontou falhas de projeto e de execução de espaços, e de mobiliário que são passíveis de correção, em curto e médio prazo, possibilitando melhor conforto e satisfação dos usuários, sejam clientes ou funcionários.

\section{REFERÊNCIAS BIBLIOGRÁFICAS}

ABNT. NBR 10152/1999 - Avaliação de ruído ambiente em recintos de edificações visando o 


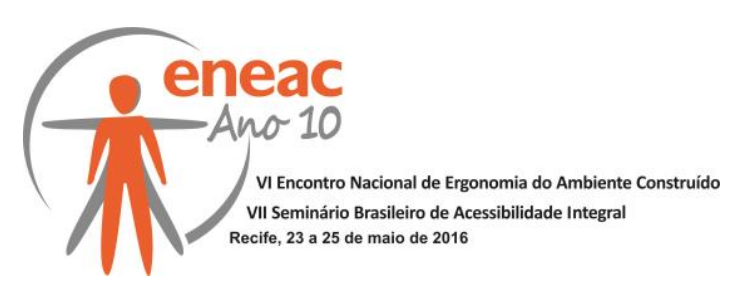

conforto dos usuários - procedimentos. Rio de Janeiro, 1999, 5p.

ABNT. NBR ISSO/CIE 8995-1 - lluminação de ambientes de trabalho. Parte 1: Interiores. Rio de Janeiro. 2013. 46p.

ABNT. NBR 9050/2015 - Acessibilidade a edificações, mobiliário, espaços e equipamentos urbanos. Rio de Janeiro, 2015. 162p.

BAUMAN, Zygmunt. Vida para consumo: a transformação das pessoas em mercadorias. Rio de Janeiro: Jorge Zahar Ed., 2008

COSTA, Tatiana; CARDOSO, Antônio Joaquim. O envolvimento das mulheres obesas com o vestuário e a moda. Atas das XVII Jornadas Hispano Lusas de Gestión Científica. Logrono, Espanha, 2007.

FALCÃO, C. S.; SOARES, M. M. Ergonomia e análise multidisciplinar do ambiente construído. III ENEAC Encontro Nacional de Ergonomia do Ambiente Construído, 2011.

LAMBERTS, R. Desempenho Térmico de Edificações. (Apostila) Universidade Federal De Santa Catarina. CTC - Departamento De Engenharia Civil Laboratório De Eficiência Energética Em Edificações, Florianópolis, 2011, 196p.

MALARD, Maria Lúcia. As aparências em arquitetura. BH: Editora UFMG, 2006, 144p.

MERLEU-PONTY, M. Fenomenologia da percepção. Rio de Janeiro: Freitas Bastos, 1971.

MINISTÉRIO DO TRABALHO. NR-17 Ergonomia. 1990. 14p.Disponível online em<http://www.guiatrabalhista.com.br/legislacao/nr/nr17.htm>. Acesso em 20 de outubro de 2015.

MORAES, A. \& MONT'ALVÃO, C. R. Ergonomia: Conceitos e Aplicações Metodologia Ergonômica. Rio de Janeiro: iUsEr, 2003, 139p.

OMS - Organização Mundial de Saúde. Obesidade: prevenindo e controlando a epidemia global. Relatório da Consultadoria da OMS, Genebra, (2004).

PANERO, Julius; ZELNIK, Martin. Dimensionamento humano para espaços interiores.Barcelona: G. Gili, 2003.

SANOFF, Henry. Visual Research Methods in Design. New York: Van Nostrand R 1991.

SBEM - Sociedade Brasileira de Endocrinologia e Metabologia. Números da Obesidade no Brasil. Disponível em: http://www.endocrino.org.br/numeros-da-obesidade-no-brasil/. Acesso: 02/11/15

SEABRA, S. da S.; BARROS, B. X. da S. Passo a passo para aplicação da metodologia de avaliação antropométrica de circulação horizontalinterna de ambientes. Anais do ENEAC 2013 - IV Encontro Nacional de Ergonomia do Ambiente Construído. Florianópolis, Santa Catarina, Maio de 2013.

VALENÇA, Lívia do Amaral. Pessoas grandes, espaços e mobiliário grandes, Greatpeople, greatspacesandfurniture.Anais do $10^{\circ}$ Colóquio de Moda - $7^{\text {a }}$ Edição Internacional $1^{\circ}$ Congresso Brasileiro de Iniciação Científica em Design e Moda, 2014. Disponível online em:http://www.coloquiomoda.com.br/anais/anais/10-Coloquio-de-Moda_2014/COMUNICACAOORAL/CO-EIXO5-MARKETING. Acesso em 28 de outubro de 2015.

VILLAROUCO, V. Tratando de ambientes ergonomicamente adequados: seriam ergoambientes? In: MONT'ALVÃO, C. \& VILLAROUCO, V. Um novo olhar para o projeto: a ergonomia no ambiente construído.Rio de Janeiro: Faperj, 2AB, 2011, 184p. 25-46pp. 